\title{
Initial study of the mutation in exon 4 of the LDLR gene in Vietnamese patients with Familial hypercholesterolemia
}

\author{
Lao Duc Thuan, Truong Kim Phuong, Le Huyen Ai Thuy
}

\begin{abstract}
Familial hypercholesterolemia (FH) has been identified as the genetic disorder disease, which is characterized by high total cholesterol, in particularly, the high level of low density lipoprotein (LDL). The normal function of low density lipoprotein receptor is obligate for the normal of lipid profile. The mutation in exon 4 of $L D L R$ gene has been identified to be responsible to FH. In current study, the PCR sequencing method was applied to analyze the mutation of exon 4 of $L D L R$ gene of forty clinical samples, which were diagnosed with FH. As the results, 29 samples of $\mathbf{4 0}$ samples, counting for $\mathbf{7 2 . 5 \%}$. Notably, the genotypes were heterogeneous. In the representative sample DA1, the mutation 355del and c.379G $>$ T (p.V106F) were found, in which, the mutation c.379G $>T$ (p.V106F) has not been previously reported previously. In conclusion, this study being the first comprehensive mutation analysis of the $L D L R$ causing FH in our country. Additionally, mutations identification in exon 4 of $L D L R$ gene is the characteristic of Vietnamese $\mathrm{FH}$ patients.
\end{abstract}

Keywords: $L D L R$, exon 4, familial hypercholesterolemia (FH), c.379G > T (p.V106F).

\section{Introduction}

Familial hypercholesterolemia (FH; MIN\#143890) is an autosomal dominant disorder characterized by elevation of serum cholesterol bound to low density lipoprotein (LDL), which promotes deposition of cholesterol in the skin (xanthelasma), tendons (xanthomas), and coronary arteries (atherosclerosis). FH has proven to be genetically associated with defects in Low density lipoprotein receptor (LDLR) gene [6]. FH is also one of the most common disease with a frequency of heterozygotes estimated to be 1:500 and a

Lao Duc Thuan

Faculty of Biotechnology, Ho Chi Minh Open University, Vietnam

Truong Kim Phuong

Faculty of Biotechnology, Ho Chi Minh Open University, Vietnam

Le Huyen Ai Thuy

Faculty of Biotechnology, Ho Chi Minh Open University, Vietnam frequency of homozygotes being round $1: 10^{6}$ in most population. Based on the statistic report of US Census Bureau, International Data Base (2014), the extrapolated prevalence of heterozygotes in Vietnam is 165,325 cases to population estimated used.

$L D L R$, also known as FHC, LDLR-human, etc., located at the $19 \mathrm{p} 13.2$ region, spans $45 \mathrm{~kb}$ and includes 18 exons which encodes the six functional domain in its mature receptor [9, $11,12]$. $L D L R$ gene consists of cell surface proteins involved in receptor-mediated the transport of LDL into cells via endocytosis, and plays a major in the clearance of lipoproteins from blood. To date, more than 1000 mutations, the most of them are point mutations, in $L D L R$ gene causing FH have been described (Genetics Home Reference: $L D L R$ gene). Many reports indicated that the point mutation on exon 4 was the high frequency mutation on the $L D L R$ gene [ 3 , $2,8,12]$. To the best of our knowledge, the study examining the mutations in $L D L R$ gene of FH in Vietnamese population has not been focused, thus, the aim of present study was to analyze the mutation in exon 4 of $L D L R$ gene in Vietnamese population with $\mathrm{FH}$.

\section{Materials and methods}

\section{A. Subjects and individuals}

In current study, 40 blood samples diagnosed with $\mathrm{FH}$ with increased total cholesterol (TC $\geq 5.2 \mathrm{mmol} / \mathrm{l}$ ), Triglyceride ( $\mathrm{T} \geq 1.9 \mathrm{mmol} / \mathrm{l})$, low density lipoprotein (LDL $\geq 3.4 \mathrm{mmol} / \mathrm{l}$ ). All samples were recruited from Thu Duc Hospital, HCMC, Vietnam. All participants provided written informed consent prior to enrollment into the study.

\section{B. DNA isolation}

Five $\mathrm{ml}$ of blood from each sample were collected, then, blood leukocytes were isolated by centrifugation at 5000 $\mathrm{rpm} /$ minutes, in 10 minutes. Genomic DNA was extracted from blood leukocytes by means of an enzyme digestion using $700 \mu \mathrm{l}$ lysis buffer $(\mathrm{NaCl} 5 \mathrm{M}$, Tris-HCl 1M, EDTA $0.5 \mathrm{M}$, SDS $10 \%$ and Proteinase $\mathrm{K} 1 \mathrm{mg} / \mathrm{ml}$ ). The samples were incubated at $56^{\circ} \mathrm{C}$ overnight. Then, genomic DNA obtained and purified by Phenol/Chloroform extraction and ethanol precipitation. The quality and purity of DNA extraction was measured by the proportion of $\mathrm{A}_{260} / \mathrm{A}_{280}$. Then, 
the DNA solution was stored at EDTA $0.5 \mathrm{M},-20^{\circ} \mathrm{C}$ for further used.

\section{PCR analysis of LDLR gene (exon} 4)

The exon 4 of $L D L R$ gene was amplified by PCR method. The sequence forward and reverse primer sequences for LDLR exon 4 amplification were, respectively, 5'ACTGCGGCAGCGTCCCCGGC -3 , and 5'TGGGGGAGCCCAGGGACAGG -3'. For PCR assay, the amplification was done in a total volume of $25 \mu \mathrm{l}$, containing $1 \mu \mathrm{g}$ DNA template. PCR reaction was subjected to initial at $95^{\circ} \mathrm{C}$ for 5 minutes, followed by 35 cycles at $95^{\circ} \mathrm{C}$ for 30 seconds, $54^{\circ} \mathrm{C}$ for 30 seconds, $72^{\circ} \mathrm{C}$ for 30 seconds, and finally $72^{\circ} \mathrm{C}$ for 10 minutes. Each PCR product was directly loaded onto a $2.0 \%$ agarose gel, stained with Ethidium bromide, and directly visualized under UV illumination. Purified DNA amplified products were directly sequenced in two directions using the amplification primers. The PCR product sequencing was read by Chroma Lite DNA sequencing software 2.6.1 (Technelysium). The results were analyzed with CLC Genomics workbench 9.5 (Qiagen Bioinformatics) and compared with referent sequence in NCBI database (NCBI reference sequence: NC_000019.10, selected region: from $11,089,362$ to $11,133,830)$. Nucleotides were numbered as suggested by Yamamoto et al and the mutations were named according to the nomenclature recommended by den Dunnen and Antonarakis.

\section{Results}

In current study, PCR-sequencing was used to analyze the mutation in exon 4 of $L D L R$ gene. The PCR products were observed by electrophoresis in distinctly different size and easily identified. The forward and reverse primer yielded a PCR product of 527 bps (Fig. 1). Then, PCR product was analyzed by DNA sequencing. The signal of peaks in PCR product sequencing were quite good for reading nucleotide and mutation analysis (Data not shown). According to Blast results, all of the PCR products were similar to Homo sapiens low density lipoprotein receptor gene, giving the representative results, it was similar to the referent sequence with accession number: FJ525879, E-value $=0.0$, Ident $=$ $99 \%$. It indicated that we successfully amplified the exon 4 of $L D L R$ gene, then, the resultant sequences were compared and analyzed with the referent sequence (NCBI reference sequence: NC_000019.10, selected region: from 11,089,362 to $11,133,830$ ) and CLC Genomics workbench 9.5 software.

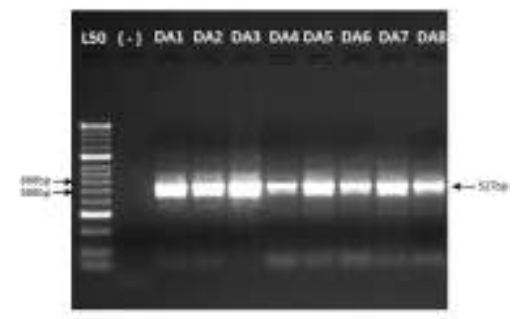

Figure 1. Agarose gel electrophoresis showing the present of PCR products in representative samples. L50: Molecular weight ladder 50 bps. DA1 to DA8: representative clinical samples. (-): negative control.

Forty clinical samples were included in this study. Different mutations in the exon 4 of $L D L R$ gene were detected in 29 of 40 samples (counting for $72.5 \%$ ). All mutations were heterozygous. The LDLR gene mutation, in representative samples DA1, included the deletion at nucleotide 355 (355del) and a substitution of valine for phenylalanine (c.379G>T (p.V106F)) (Figure 2).

(A)

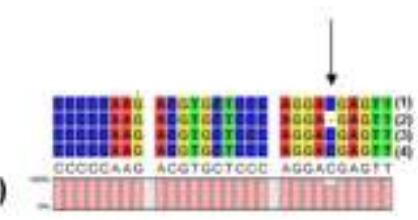

(B)

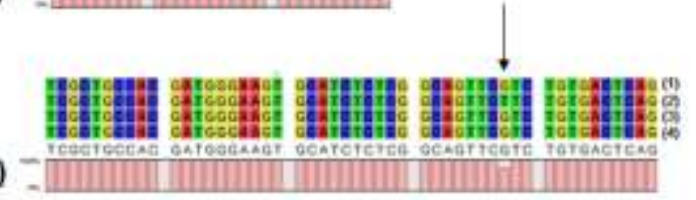

Figure 2. The partial DNA sequence of representative samples DA1 genotypes of exon 4 region in $L D L R$ gene. The mutations were signed as arrow. (A) c.355del (B) c.379G $>\mathrm{T}$ (p.V106F); (1) Referent sequence: NC_000019.10; (2): the forward strand of DA1; (3) exon 4 in $L D L R$ gene which collected from NCBI (4): the reverse-complement strand of the reverse strand of DA1.

\section{Discussion}

Forty clinical samples were included in this current study. The lipid profile parameters used in this study were total cholesterol, triglyceride and low density lipoprotein. Plasma total cholesterol ranged from 3.94 to 17.46 (mean $=6.26 \pm$ $1.99 \mathrm{mmol} / \mathrm{l})$, triglyceride ranged from 0.92 to 9.20 (mean $=$ $2.70 \pm 1.95 \mathrm{mmol} / \mathrm{l})$ and LDL levels ranged from 0.66 to $12.72($ mean $=4.10 \pm 1.82 \mathrm{mmol} / \mathrm{l})$.

Recent studies demonstrated that many different types of $L D L R$ mutation have been identified in patients with $\mathrm{FH}$ worldwide, including nucleotide substitutions, large rearrangements, nucleotide deletion, etc. that leading to the disorder of its function $[6,8,10]$. The gene for $L D L R$ spans $45 \mathrm{kbs}$, divided into 18 exons, and the correspondence between gene exons and its functions have been well established [11] According to a systematic review of Südhof et al. (1985), most of mutations were located in exon 4 of LDLR and approximately $60 \%$ of the mutations were missense mutations. It could be explained that exon 4 encode the ligand binding domain, which is made up of seven repeats of 40 amino acids each and it is important and necessary for ligand binding [11]. In our study, we represented the first description of heterozygous mutations in the exon 4 of the gene for $L D L R$ in Vietnamese patients with hypercholesterolemia. In previous studies, the prevalence of 
Proc. of Sixth International Conference On Advances in Applied Science and Environmental Engineering - ASEE 2016 Copyright (C) Institute of Research Engineers and Doctors. All rights reserved.

ISBN: 978-1-63248-108-5 doi: 10.15224/ 978-1-63248-108-5 -41

exon 4 of $L D L R$ gene were $12.1 \%$ in Spanish population and $7.7 \%$ in Venezuelan Population $[1,2]$, made the comparison, in our study, the results showed that 29 cases of 40 cases, counting for $72.5 \%$, which was completely higher. In our initial study, all of 40 clinical samples were collected from FH patients, thus, we initial concluded that the $72.5 \% \mathrm{FH}$ patients containing the mutation on exon 4 of the $L D L R$ gene. Notably, the prevalence of exon 4 mutation was almost heterozygous. Regarded to the representative samples DA1, we found out the two mutations, which were deletion at nucleotide 355 ( $355 \mathrm{del})$, which causes a frameshift mutation, and a substitution of valine for phenylalanine (c.379G $>\mathrm{T}$ (p.V106F)). Compared to the list of LDLR gene mutation databases, the $335 \mathrm{del}$ mutation in our study was previously reported by Jensen et al. (1996). In particular, the c.379G $>$ T (p.V106F) mutation was firstly identified in Vietnamese population, which have not been reported worldwide when compared to the list of $L D L R$ gene mutation. In this initial study, we have indicated that the mutations in exon 4 of $L D L R$ gene is the characteristic of $\mathrm{FH}$ in Vietnamese patients with the prevalence of $72.5 \%$. It was noted that, approximately $30 \%$ patients in current study may carry other mutations on different exons of $L D L R$ gene, or on different genes, such as $A p o B$ and $P S K 9$, which have been reported to be associated to $\mathrm{FH}$.

\section{v. Conclusion}

In summary, this initial study was carried out to evaluate the prevalence of mutation cases in Vietnamese population, which focused on the exon 4 of $L D L R$ gene. We have found 29 cases of 40 samples collected from Vietnamese population. In the representative samples DA1, we found out the mutation 355del, which was previously identified, and c.379G>T (p.V106F), which was the novel mutation in exon 4 of $L D L R$ gene in Vietnamese population. The heterozygous genotypes with exon 4 of $L D L R$ gene is the characteristic of FH in Vietnamese population. Further large-scale study is required in order to investigate and summarize the genotypes of mutation in exon 4 of the $L D L R$ gene.

\section{Acknowledgement}

This research was conducted on the support of the Ho Chi Minh City Open University, Ho Chi Minh City, Vietnam.

\section{References}

[1] K. K. Alharbi, T. S. Kashour, W. Al-Hussaini, M. S. Nbaheen, R. M. Hasanato, S. Mohamed, W. Tamimi, I. A. Khan, "Screening for genetic mutations in LDLR gene with familial hypercholesterolemia patients in the Saudi population", Acta Biochim Pol, vol. 62(3), pp. 559-562, 2015.

[2] N. Arráiz, V. Bermúdez, N. Rondon, F. Reyes, L. Borjas, E. Solís, E. Mujica, C. Prieto, N. Reyna, M. Velasco, "Novel mutations identification in exon 4 of LDLR gene in patients with moderate hypercholesterolemia in a Venezuelan population”, Am J Ther., vol. 17(3), pp. 325-329, 2010.

[3] I. N. Day, R. A. Whittall, S. D. O'Dell, L. Haddad, M. K. Bolla, V. Gudnason, S. E. Humphries, "Spectrum of LDL receptor gene mutations in heterozygous familial hypercholesterolemia", Hum Mutat., vol. 10(2), pp. 116-127, 1997.

[4] J. T. den Dunnen, S. E. Antonarakis, "Nomenclature for the description of human sequence variations", Hum Genet., vol. 109(1), pp. 121-124, 2001.

[5] Genetics Home Reference: LDLR gene (2016). https://ghr.nlm.nih.gov/gene/LDLR

[6] H. H. Hobbs, M. S. Brown, J. L. Goldstein, "Molecular genetics of the LDL receptor gene in familial hypercholesterolemia", Hum Mutat., vol. 1(6), pp. 445-466, 1992.

[7] H. K. Jensen, L. G. Jensen, P. S. Hansen, O. Faergeman, N. Gregersen, "High sensitivity of the single-strand conformation polymorphism method for detecting sequence variations in the low-density lipoprotein receptor gene validated by DNA sequencing", Clin Chem, vol. 42(8 Pt 1), pp. 1140-1146, 1996.

[8] L. Jiang, L. Y. Sun, Y. F. Dai, S. W. Yang, F. Zhang, L. Y. Wang. "The distribution and characteristics of LDL receptor mutations in China: A systematic review. Sci Rep., vol. 5, pp. 17272, 2015.

[9] V. Lindgren, K. L. Luskey, D. W. Russell, U. Francke, "Human genes involved in cholesterol metabolism: chromosomal mapping of the loci for the low density lipoprotein receptor and 3-hydroxy-3methylglutaryl-coenzyme A reductase with cDNA probes", Proc Natl Acad Sci U S A., vol. 82(24), pp. 8567-8571, 1985.

[10] A. K. Soutar, R. P. Naoumova, "Mechanisms of disease: genetic causes of familial hypercholesterolemia", Nat Clin Pract Cardiovasc Med,vol. 4(4), pp. 214-225, 2007.

[11] T. C. Südhof, J. L. Goldstein, M. S. Brown, D. W. Russell, "The LDL receptor gene: a mosaic of exons shared with different proteins", Science,vol. 228(4701), pp. 815-822, 1985.

[12] M. Varret, J. P. Rabés, R. Thiart, M. J. Kotze, H. Baron, A. Cenarro, O. Descamps, M. Ebhardt, J. C. Hondelijn, G. M. Kostner, Y Miyake, M. Pocovi, H. Schmidt, H. Schuster, M. Stuhrmann, T. Yamamura, C. Junien, C. Béroud, C. Boileau, "LDLR Database (second edition): new additions to the database and the software, and results of the first molecular analysis", Nucleic Acids Res., vol. 26(1), pp. 248-252, 1998.

[13] T. Yamamoto, C. G. Davis, M. S. Brown, W. J. Schneider, M. L. Casey, J. L. Goldstein, D. W. Russell, "The human LDL receptor: a cysteine-rich protein with multiple Alu sequences in its mRNA", Cell., vol. 39(1), pp. 27-38, 1984. 